\title{
Solar hybrid air conditioning system to use in Iraq to save energy
}

\author{
$Y . V$. Vankov $^{1}, A . K . \mathrm{Al}-\mathrm{Okbi}^{1,2, *}$, and $M . H$. Hasanen $^{2}$ \\ ${ }^{1}$ Kazan State Power Engineering University, Kazan, Russia \\ ${ }^{2}$ University of Technology, Baghdad, Iraq
}

\begin{abstract}
The energy saving issues are becoming necessary worldwide, as excessive consumption of energy leads to the consumption of a larger amount of fuel, increases environmental pollution and negatively affects the ozone layer. In Iraq, in particular, the demand for central air conditioning systems and home air conditioners with high electrical capacity has become increasingly clear in the recent years. Air conditioning systems within residential and public buildings, as well as government facilities became a necessity for good internal comfort, which was driven by desertification, high temperature, air pollution and increased population, resulting in increased consumption of electric power and pressing of power plants. Aiming at usage of renewable energy sources, the proposed system uses solar collectors as auxiliary solar thermal compressors and integrate them with air conditioning systems. The proposed solution will increase the cooling system efficiency, reduce electricity consumption and pollution.
\end{abstract}

\section{Introduction}

The high demand for air conditioners in Iraq due to high temperatures in summer (sometimes temperatures exceed 50 degrees Celsius) led to an increase in electricity consumption [1]. Air conditioning is the process of controlling the air characteristics, namely temperature, humidity, purity and distribution method to suit the application [2]. In general, air conditioning is also known as air cooling, which is a process of heat removal. This process needs energy, the source of which is usually electricity. As the load on electricity increases, the solar energy becomes attractive once the system is installed [3]. Solar energy, being one of the sources of renewable energy, is likely to be the most suitable system for installation in sub-tropical countries.

The system, which has the simplest control of capacity, mechanism, ease of implementation, high reliability, silent operation, long life and low maintenance cost, is a real candidate for the efficient and economical use of solar energy in cooling applications [4]. But this paper focuses on developing and improving the standard air conditioning unit for working with solar energy as an auxiliary system of the traditional compressor to reduce energy consumption, environmental pollution and noise.

Usage of solar energy to run an air conditioning system is a practical way to replace conventional electricity. In order to understand the solar air conditioning system, a lot of research and testing has been performed to discover the design and operation of an air conditioning system and a solar system consisting of a vacuum tube system.
The purpose of this paper is to design and construct a direct current air conditioning system, and to describe the components and characteristics of the system including its advantages and limitations. The actual performance of the system is studied based on operational view and commercial applications.

\section{Methodology}

The approaches used in this project are based on suggestions from [1], and are as follows:

a) Collection of the required meteorological data: meteorological data for Baghdad was used. A typical meteorological year (TMY) was created and the hourly, monthly and annual values of solar radiation processed.

b) Cooling load calculation: One should determine what kind of cooling is used and how much of cooling is needed.

c) Design and sizing of the air conditioning system: Using the weather data and the selected design conditions, the components of the system could be sized.

d) Optimisation of the system: The aim was to use the least cost energy, so the designed system was optimised with that in mind.

e) Material procurement and construction of the experimental system: Once the system was optimized, the components were procured and the system was constructed and tested.

f) System was evaluated. The life cycle costs for solar cooling system were calculated and competitiveness with regards to price and thermal efficiency for domestic applications were determined.

\footnotetext{
* Corresponding author: ahmedkhaleel18@yahoo.com
} 


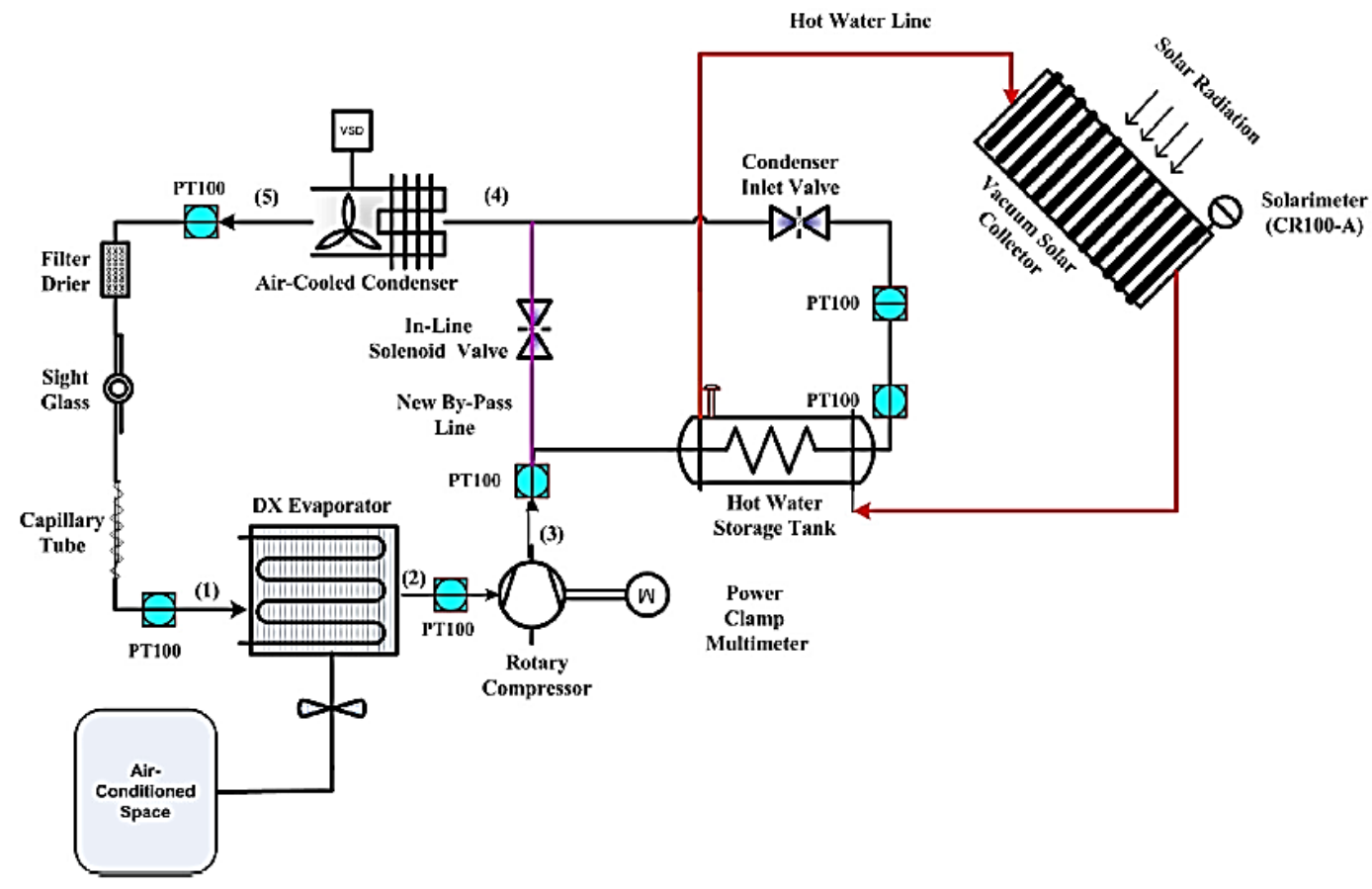

Fig. 1. Diagram of solar cooling system.

g) Analysis of results and providing recommendations: The results were analyzed and the necessary improvements were recommended. Options for improving technical effectiveness and economic competitiveness were suggested. Ways of improving research and development efforts in this field were also investigated.

\section{System description}

The proposed system concept consists of air conditioner and the vacuum tube system as indicated in figure 1 . In order to determine the characteristics and properties of all the components used, each component must be taken as a single unit.

The complete system must be able to operate in stable conditions, and, if possible, to achieve the efficiency as conventional air conditioning system. For example, for the cooling purpose, performance of the DC air conditioner should be the same as that of normal AC air conditioner.

\subsection{Refrigeration load}

Heat naturally flows from warmer places to cooler places. In other words, the heat is called as refrigeration load. Refrigeration equipment such as air conditioner is used to transfer heat from a cooler place to a warmer place. For example, the heat inside a house is absorbed and is transferred outside [5].

The refrigeration load is the rate at which heat must be removed from the refrigerated space in order to produce and maintain the desired temperature conditions. The total cooling load on the refrigerating equipment is the sum of heat gain from several different sources which include heat gained from walls, windows and doors [6].

There are several factors which should be considered while determining the cooling load [7], namely:

- Site, i.e. size and construction of the cooling area;

- Human presence, as human body continuously produces heat through a process called metabolism;

- Activity level, for example, sleeping and dancing inside of an area will give various heat rates;

- Equipment, i.e. printers, computers, etc.

\subsection{Air conditioning system}

Either for a building or a vehicle, the air conditioner mainly consists of five key components which are compressor, refrigerant, expansion device, evaporator and condenser [8].

As shown in figure 2, an electrically operated compressor can be described as the heart of an air conditioning system as it pumps refrigerant throughout the system. The main function of compressor is to compress refrigerant vapour to high pressure, making it hot for the refrigerant circulation process [9]. 


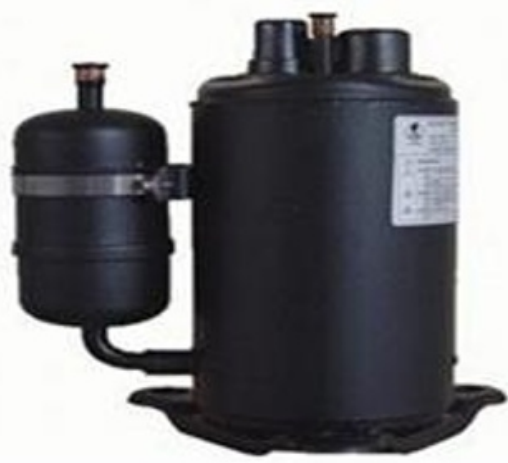

Fig. 2. Air conditioner compressor.

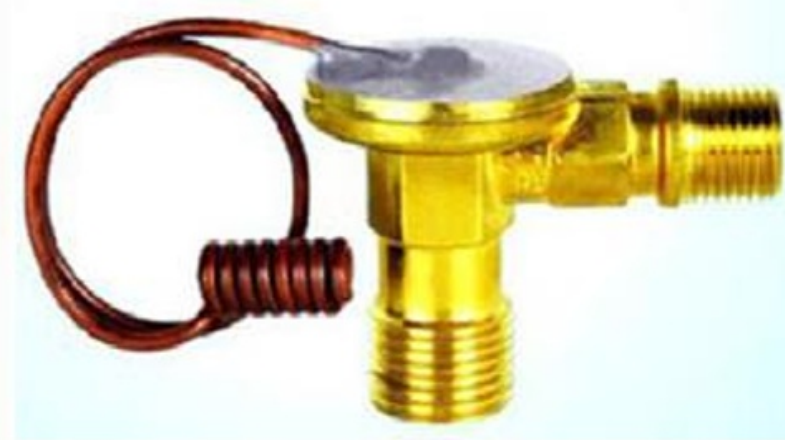

Fig. 3. Expansion device for air conditioning system.

Refrigerant is a material that acts as a cooling agent by absorbing heat into the system and circulating inside the circuit of the air conditioning system [10].

Located between condenser and evaporator, the expansion device allows a controlled amount of liquid refrigerant to flow into the low-pressure section of the process $[11,12]$. Figure 3 illustrates the expansion device used in air conditioning system.

For the refrigerant circulation process, evaporator uses the liquid state refrigerant to absorb heat from the cooling space into the system [13]. As shown in figure 4, the evaporator is located inside the indoor unit installed in the cooling area.

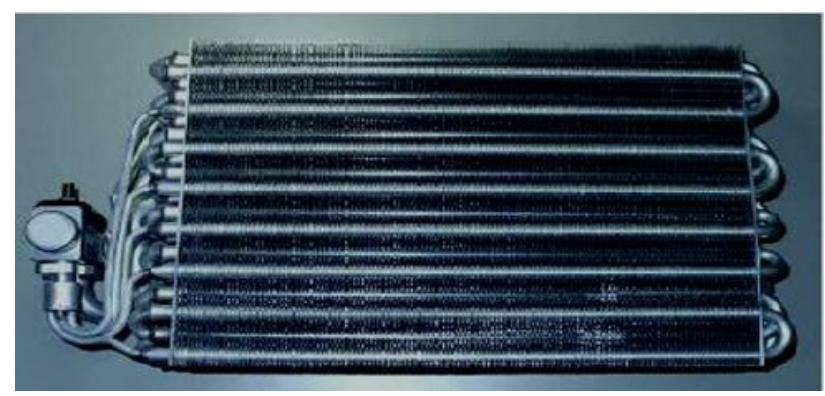

Fig. 4. Evaporator coil.

At condenser, where the refrigerant temperature is low, the heat from the system that is absorbed by evaporator is being removed. The condenser presented in figure 5 is located inside the outdoor unit with the compressor.

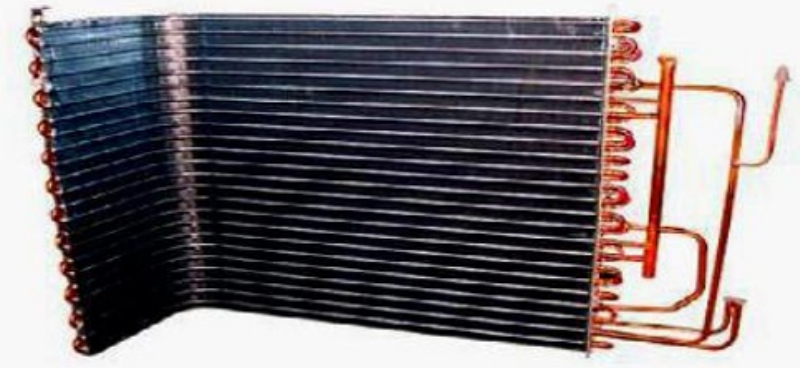

Fig. 5. Condenser coil.

\subsection{The vacuum tube system}

A solar collector is a device that collects and/or concentrates solar radiation from the Sun. These devices are primarily used for active solar heating and allow water heating for personal use. These collectors are generally mounted on a roof and should be very sturdy as they are exposed to variety of weather conditions.

This type of solar collector, as shown in figure 6, uses a series of evacuated tubes to heat water. These tubes utilize vacuum or evacuated space, to capture the Sun energy while minimizing the heat losses to the surroundings. They have an inner metal tube which acts as the absorber plate, which is connected to a heat pipe, and transfers heat collected from the Sun to water. In this heat pipe the fluid is essentially under a very particular pressure $[14,15]$. Under this pressure, the "hot" end of pipe has boiling liquid in it, while the "cold" end is filled with condensing vapour. This allows the thermal energy to move more efficiently from one end of the pipe to the other one. Once the heat from the Sun moves from the hot end of the heat pipe to the condensing end, the thermal energy is transferred to water being heated for use.

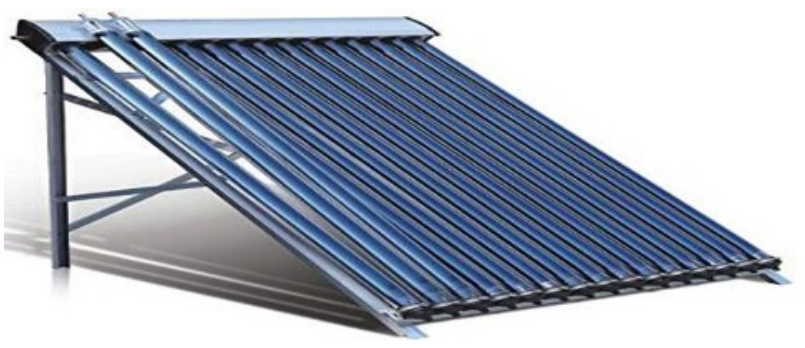

Fig. 6. A diagram of an evacuated tube solar collector.

\subsection{System operation}

Solar energy is received by the unloaded unit and converted to heat energy by water. The thermal energy is then collected by a thermal tank and transported by the thermal transfer medium (water) to a heat exchanger that increases the cooling gas temperature from the compressor.

The most common type of air conditioning is technically referred to as direct expansion, mechanical, vapour-compression refrigeration system. The goal of air conditioning is to capture heat in the cooling space and throw it outside [16]. The operation of the system starts 


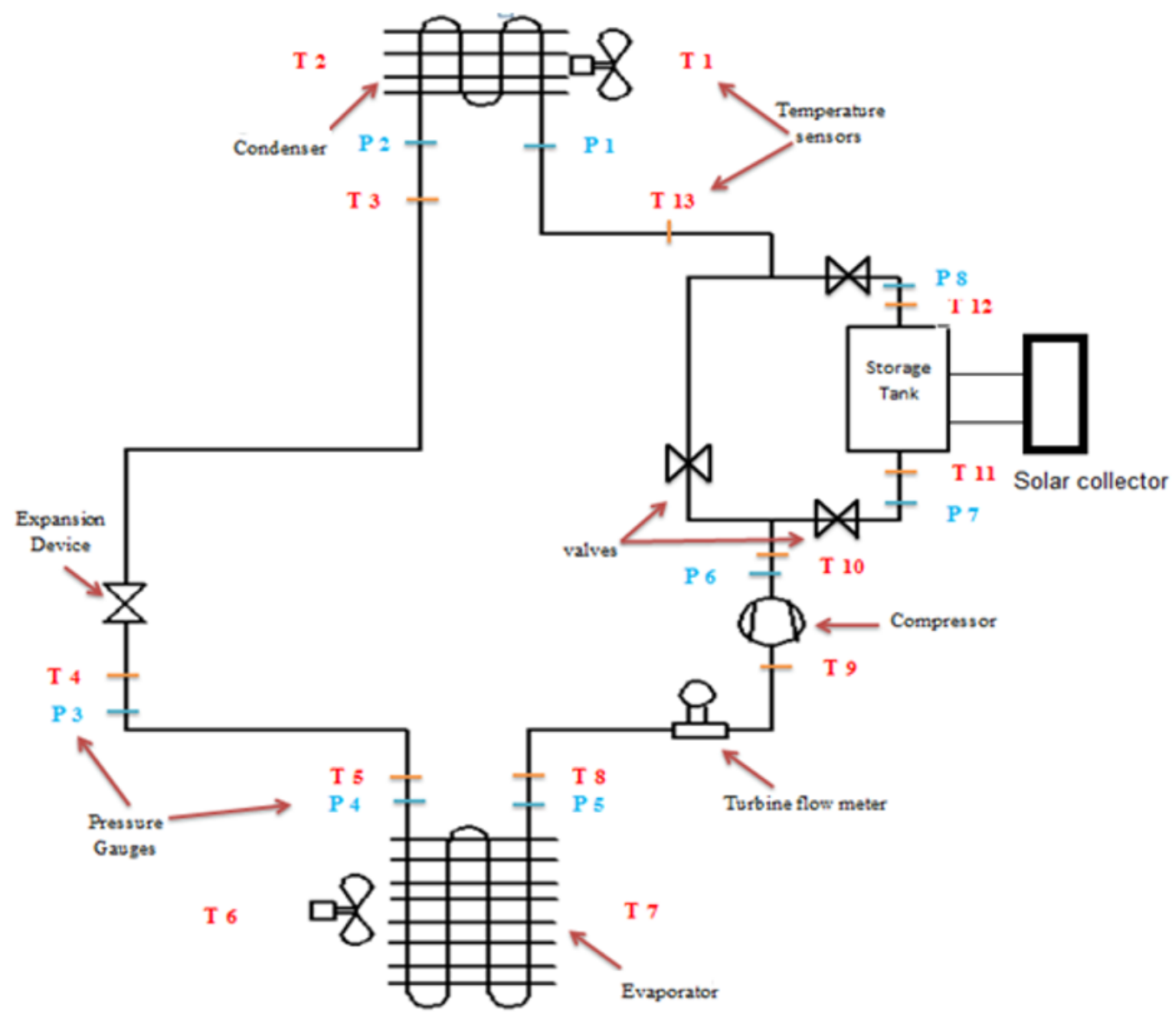

Fig. 7. Air conditioning system: 1. Compressor; 2. Solar collector \& storage tank; 3. Condenser; 4. Expansion device; 5. Evaporator.

when a cold, low pressure liquid (refrigerant) flows across the evaporator coil inside the cooling space to absorb heat. The cold liquid that enters the evaporator coil comes out as a low pressure gas. Then, the cooled low pressure gas is taken outside and compressed by the compressor to become a hot, high pressure gas. Next, the hot gas is passed through the condenser coil and gives off some of its heat as outdoor air is blown across the coil. This causes the hot gas to condense back to warm liquid. The warm liquid is carried back to the evaporator by passing through the expansion device which decreases the temperature and pressure of the liquid. Figure 4 shows the basic air conditioning operation.

\section{Conclusions}

The main objective of this research is to improve the performance of the split air conditioning system unit and to improve energy saving at high ambient room temperature. Experimental and mathematical investigations must be carried out to achieve this goal, so the following steps should be performed:

- Integration the $\mathrm{A} / \mathrm{C}$ system with the solar collector of the vacuum tube to perform maximum performance improvement and energy saving.

- Conduction a comparative study of performance of the conventional and split air conditioning systems.
However, the current research showing the implementation of the solar air-conditioning system of the cryogenic compression system type using a solar collector vacuum tube is an attempt to improve the thermal performance of the air conditioning system and to reduce electricity consumption in Iraq.

\section{References}

[1] M. H. Hasanen, J. H. Laith, J.A. Orhan, Investigation on Solar Hybrid Cooling System with High Latent Cooling Load Advances in Environmental Biology, 11(4), 24-36 (2017)

[2] D. S. Kima, C. A., Infante Ferreirab, Solar refrigeration options - a state-of-the-art review international journal of refrigeration 31, 3-15 (2008)

[3] I.A. Khaleel, Is Iraq Ready to Use Solar Energy Applications: A Review International Journal of Engineering Science Invention, 6(10), 27-42 (2017)

[4] T. T. Chow, A review on photovoltaic/thermal hybrid solar technology, Applied Energy 87, 365-379 (2010)

[5] X. B. Bu, H. S. Li, L. B. Wang, Performance analysis and working fluids selection of solar powered organic Rankine-vapor compression ice maker Solar Energy 95, 271-278 (2013)

[6] Mehdi Zeyghami, D. YogiGoswami, Elias Stefanakos, A review of solar thermo-mechanical 
refrigeration and cooling methods, Renewable and Sustainable Energy Reviews, 51, 1428-1445 (2015)

[7] S. Mekhilefa, R. Saidurb, A. Safari, A review on solar energy use in industries, Renewable and Sustainable Energy Reviews, 15, 1777-1790 (2011)

[8] S.B. Mahmut, B.R. Saffa, Building integrated solar thermal collectors - A review, Renewable and Sustainable Energy Reviews, 51, 327-346 (2015)

[9] Hoy-Yen Chan, Saffa B. Riffat, Jie Zhu, Review of passive solar heating and cooling technologies, Renewable and Sustainable Energy Reviews, 14, 781-789 (2010)

[10] Szabolcs Varga, Armando C. Oliveira and Bogdan Diaconu, Analysis of a solar-assisted ejector cooling system for air conditioning, International Journal of Low-Carbon Technologies, 4, 2-8 (2009)

[11] Lin Zheng, Wei Zhang, Lingzhi Xie, Wei Wang, Hao Tian and Mo Chen, Experimental study on the thermal performance of solar air conditioning system with MEPCM cooling storage, International Journal of Low-Carbon Technologies, 14, 83-88 (2019)

[12] Ursula Eicker, Dirk Pietruschka, Design and performance of solar powered absorption cooling systems in office buildings, Energy and Buildings 41 81-91 (2009)

[13] N. Gunasekar, M. Mohanraj, V. Velmurugan, Artificial neural network modeling of a photovoltaicthermal evaporator of solar assisted heat pumps, Energy 93, 908-922 (2015)

[14] H. Z. Hassan, A. A. Mohamad, A review on solar cold production through absorption technology, Renewable and Sustainable Energy Reviews, 16, 53315348 (2012)

[15] Bourhan Tashtoush, Aiman Alshare, Saja AlRifai, Hourly dynamic simulation of solar ejector cooling system using TRNSYS for Jordanian climate, Energy Conversion and Management, 100, 288-299 (2015)

[16] J. Sieckera, K. Kusakana, B.P. Numbi, A review of solar photovoltaic systems cooling technologies, Renewable and Sustainable Energy Reviews, 79, 192-203 (2017) 